\title{
Comparison of different insulin pump makes under routine care conditions in adults with Type 1 diabetes
}

DOI:

10.1111/dme.13412

\section{Document Version}

Accepted author manuscript

Link to publication record in Manchester Research Explorer

\section{Citation for published version (APA):}

Leelarathna, L., Roberts, S. A., Hindley, A., Markakis, K., Alam, R., Chapman, A., Morris, J., Urwin, A., Jinadev, P., \& Rutter, M. (2017). Comparison of different insulin pump makes under routine care conditions in adults with Type 1 diabetes. Diabetic Medicine, 34(10), 1372-1379. https://doi.org/10.1111/dme.13412

\section{Published in:}

Diabetic Medicine

\section{Citing this paper}

Please note that where the full-text provided on Manchester Research Explorer is the Author Accepted Manuscript or Proof version this may differ from the final Published version. If citing, it is advised that you check and use the publisher's definitive version.

\section{General rights}

Copyright and moral rights for the publications made accessible in the Research Explorer are retained by the authors and/or other copyright owners and it is a condition of accessing publications that users recognise and abide by the legal requirements associated with these rights.

\section{Takedown policy}

If you believe that this document breaches copyright please refer to the University of Manchester's Takedown Procedures [http://man.ac.uk/04Y6Bo] or contact uml.scholarlycommunications@manchester.ac.uk providing relevant details, so we can investigate your claim.

\section{OPEN ACCESS}




\title{
Comparison of different insulin pump makes under
}

\section{routine care conditions in adults with Type 1 diabetes}

Short title: Comparison of different insulin pumps

L. Leelarathna ${ }^{1,2}$, S. A. Roberts ${ }^{3}$, A. Hindle ${ }^{2}$, K. Markakis ${ }^{1}$, T. Alam ${ }^{2}$, A.

Chapman $^{1}$, J. Morris ${ }^{1}$, A. Urwin ${ }^{1}$, P. Jinadev ${ }^{1}$ and M. K. Rutter ${ }^{1,2}$

\begin{abstract}
${ }^{1}$ Manchester Diabetes Centre, Central Manchester University Hospitals NHS Foundation Trust, Manchester Academic Health Science Centre, ${ }^{2}$ Division of Diabetes, Endocrinology and Gastroenterology, University of Manchester and ${ }^{3}$ Centre for Biostatistics, Manchester Academic Health Science Centre, University of Manchester, Manchester, UK
\end{abstract}

Correspondence to: L. Leelarathna. E-mail: lalantha.leelarathna@cmft.nhs.uk

\section{What's new?}

- Continuous subcutaneous insulin infusion (CSII) is often considered the 'gold standard' insulin replacement therapy for individuals with Type 1 diabetes.

- This is the first study to compare long-term changes in $\mathrm{HbA}_{1 \mathrm{c}}$ associated with different makes of pump under routine care conditions.

- We found no significant differences in $\mathrm{HbA}_{1 \mathrm{c}}$ improvement when comparing different makes of insulin pump, including a comparison of patch pumps and traditional This article has been accepted for publication and undergone full peer review but has not been through the copyediting, typesetting, pagination and proofreading process, which may lead to differences between this version and the Version of Record. Please cite this article as doi: 10.1111/dme.13412 This article is protected by copyright. All rights reserved. 
catheter pumps, and pre-specified patient subgroups stratified by pre-CSII $\mathrm{HbA}_{1 \mathrm{c}}$, age and diabetes duration.

- The choice of CSII make should not be influenced by the desired degree of $\mathrm{HbA}_{\mathrm{lc}}$ lowering.

\begin{abstract}
Aims To compare long-term $\mathrm{HbA}_{1 \mathrm{c}}$ changes associated with different insulin pumps during routine care in a large cohort of adults with Type 1 diabetes representative of other clinic populations.
\end{abstract}

Methods Observational, retrospective study of 508 individuals starting pump therapy between 1999 and 2014 (mean age, 40 years; 55\% women; diabetes duration, 20 years; 94\% Type 1 diabetes; median follow-up, 3.7 years). Mixed linear models compared covariateadjusted $\mathrm{HbA}_{1 \mathrm{c}}$ changes associated with different pump makes.

Results The pumps compared were: 50\% Medtronic, 24\% Omnipod, 14\% Roche and 12\% Animas. Overall $\mathrm{HbA}_{1 \mathrm{c}}$ levels improved and improvements were maintained during a followup extending to 10 years $\left(\mathrm{HbA}_{1 \mathrm{c}}\right.$ : pre-continuous subcutaneous insulin infusion (pre-CSII) vs. 12 months post CSII, $71(61,82)$ vs. $66(56,74) \mathrm{mmol} / \mathrm{mol} ; 8.7(7.7,9.6)$ vs. $8.2(7.3,8.9) \%$; $P<0.0001)$. The percentage of individuals with $\mathrm{HbA}_{1 \mathrm{c}} \geq 64 \mathrm{mmol} / \mathrm{mol}(8.0 \%)$ reduced from a pre-CSII level of $68 \%$ to $55 \%$. After adjusting for baseline confounders, there were no between-pump differences in $\mathrm{HbA}_{1 \mathrm{c}}$ lowering $(P=0.44)$, including a comparison of patch pumps with traditional catheter pumps $(P=0.63)$. There were no significant $(P<0.05)$ between-pump differences in $\mathrm{HbA}_{1 \mathrm{c}}$ lowering in pre-specified subgroups stratified by prepump $\mathrm{HbA}_{1 \mathrm{c}}$, age or diabetes duration. $\mathrm{HbA}_{1 \mathrm{c}}$ lowering was positively related to baseline 
$\mathrm{HbA}_{1 \mathrm{c}}(P<0.001)$ and diabetes duration $(P=0.017)$, and negatively related to the number of years of CSII use $(P=0.024)$.

Conclusions Under routine care conditions, there were no covariate-adjusted differences in $\mathrm{HbA}_{1 \mathrm{c}}$ lowering when comparing different pump makes, including a comparison of patch pumps vs. traditional catheter pumps. Therefore, the choice of CSII make should not be influenced by the desired degree of $\mathrm{HbA}_{1 \mathrm{c}}$ lowering.

\section{Introduction}

Continuous subcutaneous insulin infusion (CSII) is often considered the 'gold standard' of insulin replacement therapy for individuals with Type 1 diabetes [1].

Use of CSII has been shown to reduce both $\mathrm{HbA}_{1 \mathrm{c}}$ and the incidence of severe hypoglycaemia [2]. Furthermore, a recent large observational study from Sweden has shown lower cardiovascular mortality among people with Type 1 diabetes treated using a pump compared with those treated with multiple daily insulin injections, despite similar $\mathrm{HbA}_{1 \mathrm{c}}$ levels between the groups [3]. However, there is large variation in the availability of CSII between and within countries [4].

Despite significant improvements in care, including the wider use of CSII, many individuals with Type 1 diabetes fail to meet current glycaemic targets [5]. Recent data from the T1D Exchange show that $>70 \%$ in all age groups are not meeting current $\mathrm{HbA}_{1 \mathrm{c}}$ targets [6]. Similarly, data from UK show that fewer than one-third of people with Type 1 diabetes achieve $\mathrm{HbA}_{1 \mathrm{c}}$ levels $<7.5 \%$ [5]. It is of note that $\mathrm{HbA}_{1 \mathrm{c}}$ levels achieved in the $\mathrm{UK}$ are far worse than in other western European countries like Germany or France, and the proportion of individuals using CSII is also low in the UK. 
Several recent observational studies have evaluated the effect of CSII on glycaemic control in everyday clinical practice showing sustained benefit over prolonged periods [7-9]. However, no study has compared the effect of different pump makes under real-life conditions. Traditional pumps such as Medtronic, Roche and Animas deliver insulin via a catheter inserted under the skin with tubing between the pump and the cannula. By contrast, Omnipod is a 'patch pump' consisting of a handheld controller and a disposable pod that delivers insulin.

Two reports have suggested lower dose accuracy for the Omnipod insulin pump compared with traditional pumps [10] and to another patch pump [11]. By contrast, inaccuracy in basal insulin delivery has been reported with the movement of conventional pumps in relation to the catheter (pumping upwards and downwards) due to a siphon, whereas the Omnipod performed better [12].

There are also differences in the bolus calculators employed by traditional pumps including differences in the algorithmic rules that govern advice for correctional boluses, differences in the way the correction bolus/targets are set and the way the insulin on board is taken into account $[13,14]$. However, the clinical relevance of these differences is still unknown. Therefore, we designed a study to test the hypothesis that there would be clinically relevant differences in $\mathrm{HbA}_{1 \mathrm{c}}$ between pumps. Our objective was to compare long-term changes in $\mathrm{HbA}_{1 \mathrm{c}}$ associated with different insulin pumps during routine care in a large cohort of adults with Type 1 diabetes that would be representative of other clinic populations. 


\section{Research design and methods}

This large retrospective observational cohort study was conducted at Manchester Diabetes Centre, a tertiary referral and one of the largest insulin pump centres in the UK ( $>500$ active pump users and $\sim 40 \%$ of all people with Type 1 diabetes are CSII treated). All individuals who initiated CSII use between January 1999 and March 2014 were included. Individuals without a CSII start date (usually those who transferred care from another centre) and those without relevant pre-CSII data were not included.

In line with current guidance [15], indications for CSII included poor glycaemic control, problems with hypoglycaemia and glycaemic variability/erratic control.

Demographic variables and $\mathrm{HbA}_{1 \mathrm{c}}$ data were obtained from electronic records. $\mathrm{HbA}_{1 \mathrm{c}}$ data were collected from 12 months before and up to 10 years after initiation of CSII. Mean annual $\mathrm{HbA}_{1 \mathrm{c}}$ values were used for all calculations.

Prior to starting CSII, individuals received individualized counselling and education, and were offered a choice of the insulin pumps available in the UK at the time. These consisted of pumps manufactured by Animas (2020 \& Vibe; Animas Corp., West Chester, PA, USA), Medtronic (Paradigm 515, 715, 522, 722, Veo 554, 754; Minimed Inc., Northridge, CA, USA), Omnipod (Insulet Corp., Bedford, MA, USA) and Roche (Spirit, Accu-chek Combo, Accu-Chek D-Tron Plus; Roche Diabetes Care AG, Burgdorf, Switzerland). Animas, Medtronic and Roche are traditional catheter pumps where insulin delivery is via a subcutaneously placed metal or plastic cannula connected to the pump by tubing. By contrast, Omnipod is a patch pump without tubing, where a disposable pod filled with insulin is attached to the skin. In both traditional and patch pumps, it is advised that cannulas and pods be changed every third day. Approximately $20 \%$ of the individuals participated in a local structured education course lasting 3 days ( 18-20 h). The remainder received $1-3 \mathrm{~h}$ of individualized training/re- 
training on carbohydrate counting and other aspects of manging diabetes before starting pump use. In addition, training required to operate the pump, including sick day rules and pump troubleshooting, was provided in a 3-4 h session. There was no requirement to undertake a formal structured education programme before starting CSII (this practice has changed since 2015 and all patients are now required to undertake a DAFNE programme before referred for CSII). Initial basal rates were set using established methods (75\% of total daily dose on multiple daily injections divided by 2 and divided by $24 \mathrm{~h}$ to obtain hourly rates). All individuals were started on a single hourly basal rate with subsequent adjustment by patient and pump educators. Carbohydrate ratios (meal-time carbohydrate (g)/unit of insulin) were obtained using the 500 rule (500/total daily dose on pump) and sensitivity factor (glucose lowering mmol/L/unit) using the 100 rule (100/total daily dose on pump). Insulin action time was typically set for $4 \mathrm{~h}$ and individualized pre-meal glucose targets were set (typically 5 to $7 \mathrm{mmol} / \mathrm{L}$ ). Patients then received follow-up care as determined by their individual requirements.

\section{Statistical analysis}

All analyses were based on the period from initiation of pump therapy to discontinuation of pump use or switching to another pump model. Kaplan-Meier survival curves and log rank tests were used to compare the length of time pumps remained in use, as defined by termination of use or switching to another type.

Data were visualized as box plots/scatter plots of $\mathrm{HbA}_{1 \mathrm{c}}$ and its change from pre-pump baseline against years on pump and baseline $\mathrm{HbA}_{1 \mathrm{c}}$, along with smoothed fitted lines from a longitudinal regression model with quadratic terms in baseline $\mathrm{HbA}_{1 \mathrm{c}}$ and year on pump, a linear term in the calendar year the pump was fitted and a patient random effect to allow for correlation between repeat measures on the same individuals. 
A similar mixed linear model for $\left(\mathrm{HbA}_{1 \mathrm{c}}\right.$-baseline value) was used for comparison of the different pump models and patient/treatment characteristics: calendar year of pump commencement (linear, centred on 2011), sex (base male), age started pump (per decade, centred at median age), diabetes duration (linear, centred on median duration) and baseline $\mathrm{HBA}_{1 \mathrm{c}}$ (quadratic, centred on median value). All $P$-values are two-tailed and values $<0.05$ were considered statistically significant. All analyses were conducted in the $R$ statistical environment, version 3.0 (R Core Team, Vienna, Austria; https://www.R-project.org/)

\section{Results}

The CSII database included 613 individuals up to March 2014. Thirty-eight individuals were excluded due to the lack of a CSII start date, usually because start of CSII had occurred at another centre prior to transfer to our unit. Of the remaining 575, pre- and post-CSII $\mathrm{HbA}_{1 \mathrm{c}}$ data were available in 508 ( $83 \%$ of the original 613 individuals).

Demographics for the whole cohort and the subgroups treated with the four different makes of pump at baseline and to year 5 are shown in Tables 1 and S3. Median duration of followup was $3.7(2.5,5.1$ years). The majority (94\%) of participants had Type 1 diabetes, with the remainder largely consisting of individuals with secondary diabetes due to pancreatitis. Median (interquartile range (IQR)) age at the start of pump use was $40(30,49)$ years and median diabetes duration was $20(11,29)$ years. Initial pump models were: 50\% Medtronic, 24\% Omnipod (patch pump), 14\% Roche and 12\% Animas. Statistically significant differences were noted between choice of the different pump manufacturers in terms of age, sex, diabetes duration, year starting CSII and duration of follow-up. In particular, most of the CSII devices initiated in the early years (2000-2010) were Medtronic pumps, whereas the most commonly initiated CSII models between 2011 and 2014 were from Omnipod. As a 
consequence, Medtronic pump users had a longer follow-up, and Omnipod users had a shorter follow-up. Among Omnipod users, 55\% were men, whereas the majority of users of the other pumps were women. There was no statistical difference in pre-pump $\mathrm{HbA}_{1 \mathrm{c}}$ between the different pump users $(P=0.22)$, but numerically, Omnipod users had the lowest median $\mathrm{HbA}_{1 \mathrm{c}}(68 \mathrm{mmol} / \mathrm{mol})$ and Roche pump users the highest $(74 \mathrm{mmol} / \mathrm{mol})$.

The length of time for which a particular pump was used before discontinuation or switching to another type did differ between pump types $(P=0.002$ in a log rank test), with $81 \%(95 \%$ confidence interval (CI) 72-91\%) still using the Roche pump after 3 years, compared with 96\% (95\% CI: 94-98\%) Medtronic, 96\% (95\% CI: 91-100\%) Animas and 99\% (95\% CI: 96-100\%) Omnipod (Fig. S3).

\section{Overall changes in $\mathrm{HbA}_{1 \mathrm{c}}$ : combined data on individuals treated with all pump models}

The median (IQR) $\mathrm{HbA}_{1 \mathrm{c}}$ for the whole cohort pre-CSII was $71(62,83) \mathrm{mmol} / \mathrm{mol}(8.7$ (7.7, 9.6)\%), improving to $66(56,74) \mathrm{mmol} / \mathrm{mol}(8.2(7.3,9.0) \%)$ during the first 12 months (paired difference: $4(-2,12) \mathrm{mmol} / \mathrm{mol} ; P<0.0001)$. Although there was wide variability in individual responses (Fig. 1a), overall improvements in $\mathrm{HbA}_{1 \mathrm{c}}$ were maintained for up to 10 years (Fig. 1; Tables S1 and 2).

Individuals with poorer glycaemic control at baseline showed larger improvements in $\mathrm{HbA}_{1 \mathrm{c}}$ compared with those with better control (Fig. 1b). For example, there was negligible improvement in individuals with baseline $\mathrm{HbA}_{1 \mathrm{c}}$ values $<60 \mathrm{mmol} / \mathrm{mol}$, but improvements of up to $30 \mathrm{mmol} / \mathrm{mol}$ in those with pre-CSII $\mathrm{HbA}_{1 \mathrm{c}}$ levels of $\sim 120 \mathrm{mmol} / \mathrm{mol}$. The proportion of individuals with poor control $\left(\mathrm{HbA}_{1 \mathrm{c}}>64 \mathrm{mmol} / \mathrm{mol} ; 8.0 \%\right)$ was reduced from $68 \%$ (preCSII) to 55\% (at year 1), and this proportion remained stable during subsequent follow-up (Tables 1, S1 and S2). 


\section{Quantifying between-pump differences in $\mathrm{HbA}_{1 \mathrm{c}}$ lowering}

In unadjusted models that included all $\mathrm{HbA}_{1 \mathrm{c}}$ values $(n=1786)$ in all individuals $(n=480)$, there were no between-pump differences in $\mathrm{HbA}_{1 \mathrm{c}}$ change from baseline $(P=0.25$; Fig. $2 \mathrm{a})$. In similar models that adjusted for differences in baseline covariates (age, sex, baseline $\mathrm{HbA}_{1 \mathrm{c}}$, year of pump start, and diabetes duration), there were also no between-pump differences in $\mathrm{HbA}_{1 \mathrm{c}}$ change from baseline $(P=0.44$; Fig. $2 \mathrm{~b}$ and Table 2$)$.

\section{Factors associated with $\mathrm{HbA}_{1 \mathrm{c}}$ improvement}

Table 2 expands on the data presented in Fig. 2(b) by quantifying covariate effects along with the adjusted overall changes in $\mathrm{HbA}_{1 \mathrm{c}}$ from baseline in individuals treated using different pump models. These data show that $\mathrm{HbA}_{1 \mathrm{c}}$ lowering was positively related to baseline $\mathrm{HbA}_{1 \mathrm{c}}$ and diabetes duration, and negatively related to number of years on CSII therapy such that: a 1 unit higher baseline $\mathrm{HbA}_{1 \mathrm{c}}$ level was associated with $0.36 \mathrm{mmol} / \mathrm{mol}$ greater $\mathrm{HbA}_{1 \mathrm{c}}$ lowering during follow-up, which translates to an improvement in $\mathrm{HbA}_{1 \mathrm{c}}$ of $26 \mathrm{mmol} / \mathrm{mol}$ for an individual with a pre-CSII $\mathrm{HbA}_{1 \mathrm{c}}$ of $120 \mathrm{mmol} / \mathrm{mol}$ compared with zero improvement in $\mathrm{HbA}_{1 \mathrm{c}}$ for an individual with an pre-CSII $\mathrm{HbA}_{1 \mathrm{c}}$ of $49 \mathrm{mmol} / \mathrm{mol}$. The results presented in Table 2 also show that a 1-year longer diabetes duration was associated with $0.1 \mathrm{mmol} / \mathrm{mol}$ greater $\mathrm{HbA}_{1 \mathrm{c}}$ lowering during follow-up; and a 1-year longer duration of CSII therapy was associated with $0.11 \mathrm{mmol} / \mathrm{mol}$ lesser $\mathrm{HbA}_{1 \mathrm{c}}$ lowering during follow-up. Sex and age were not significantly associated with CSII improvement. A weak effect between duration of diabetes prior to CSII start and improvement was noted $(0.10 \mathrm{mmol} / \mathrm{mol}$ per year of diabetes before CSII, $P=0.017)$. 


\section{Between-pump differences in $\mathrm{HbA}_{1 \mathrm{c}}$ lowering in pre-specified patient subgroups}

Figures 2(c,d) and S2 show no between-pump differences in unadjusted $\mathrm{HbA}_{1 \mathrm{c}}$ changes in subgroups stratified by pre-pump $\mathrm{HbA}_{1 \mathrm{c}}(<64$ and $\geq 64 \mathrm{mmol} / \mathrm{mol}(<8.0 \%$ and $\geq 8.0 \%)$; Fig. 2c); age ( $<45$ and $\geq 45$ years; Fig. S2a) and diabetes duration $(<20$ and $\geq 20$ years; Fig. S2c). Similarly, in covariate-adjusted models (Fig. 2d and Fig. S2b,d) there were no between-pump differences in $\mathrm{HbA}_{1 \mathrm{c}}$ changes in subgroups stratified by pre-pump $\mathrm{HbA}_{1 \mathrm{c}}$ (Fig. 2d); age (Fig. S2b) and diabetes duration (Fig. S2d); the covariates being age, sex, baseline $\mathrm{HbA}_{1 \mathrm{c}}$, year of pump start, and diabetes duration (when appropriate).

\section{Patch pump compared with traditional pumps}

In unadjusted and covariate-adjusted models that included all $\mathrm{HbA}_{1 \mathrm{c}}$ values, there were no significant differences in $\mathrm{HbA}_{1 \mathrm{c}}$ change from baseline when comparing individuals treated with patch pumps (Omnipod) vs. traditional pumps (Medtronic, Roche and Animas). Unadjusted difference in change $=1.8(-0.9$ to 4.5$) \mathrm{mmol} / \mathrm{mol}(P=0.20)$. Adjusted difference in change $=-0.7(-3.3$ to 2.0$) \mathrm{mmol} / \mathrm{mol}(\mathrm{P}=0.63)$.

Table S3 shows detailed information about different pump models and $\mathrm{HbA}_{1 \mathrm{c}}$ levels.

\section{Discussion}

\section{Main findings}

We show, for the first time, that under routine clinical care, there are no significant differences in $\mathrm{HbA}_{1 \mathrm{c}}$ improvement when comparing different pump makes, including a comparison of patch pumps and traditional catheter pumps. We showed similar findings in pre-specified patient subgroups stratified by pre-CSII $\mathrm{HbA}_{1 \mathrm{c}}$, age and diabetes duration. 


\section{Previous studies comparing pump devices}

Previous studies have shown higher pump accuracy for traditional pumps compared with the Omnipod pump. For example, Jahn et al. found significant between-pump differences in single dose and time-average dose accuracy when assessed using a time-stamped microgravimetric system [10]. In particular, Jahn et al. showed that the accuracy of the patch pump was lower than that of traditional pumps. In another study by Borot et al., the Omnipod pump was again the least accurate of the pumps tested [11]. However, there has been criticism of the methods used in the studies [16].

Here, we present the first clinical comparison of different pump devices for improving longterm glycaemic control. Based on our data, it appears that the clinical relevance of single dose and time-averaged dose accuracy experiments is limited. This may be due, in part, to the relatively slow absorption of insulin leading to averaged effects. Pre-CSII $\mathrm{HbA}_{1 \mathrm{c}}$ and other individual patient factors appear to have a far greater impact on $\mathrm{HbA}_{1 \mathrm{c}}$ improvement than any small differences between pumps.

The only other study that has compared clinical outcomes in individuals treated with patch pump vs. traditional catheter pumps was a short-term study in 20 individuals with Type 1 diabetes [17]. In this study, Luijf et al. assessed between-pump differences in blood glucose and plasma insulin profiles after a bolus insulin infusion immediately after placement and again after 3 days. No between-pump differences in peak glucose levels or mean plasma insulin levels were observed. These data on short-term glucose variability are consistent with our long-term data on $\mathrm{HbA}_{1 \mathrm{c}}$, although readers will be aware that $\mathrm{HbA}_{1 \mathrm{c}}$ is a poor marker of glycaemic variability. 


\section{Previous studies relating $\mathrm{HbA}_{1 \mathrm{c}}$ change to pre-CSII values}

In keeping with the published data [2,7], we found larger improvements in $\mathrm{HbA}_{1 \mathrm{c}}$ in individuals with higher pre-CSII $\mathrm{HbA}_{1 \mathrm{c}}$ values (Fig. 1). In fact, baseline $\mathrm{HbA}_{1 \mathrm{c}}$ was the only clinical or demographic factor associated with a clinically meaningful $\mathrm{HbA}_{1 \mathrm{c}}$ improvement. We observed only weak associations with diabetes duration and duration of pump therapy.

\section{Previous studies relating $\mathrm{HbA}_{1 \mathrm{c}}$ change to duration of CSII therapy}

In some published studies, the benefits of CSII either were lost or were minimal at 3-5 years of follow-up [18-20]. By contrast, we observed benefits of CSII on $\mathrm{HbA}_{1 \mathrm{c}}$ for up to 10 years of follow-up. Although our data cannot give the reasons for this long-term maintenance of benefit, this might be related to the provision of regular medical and nursing follow-up for all individuals.

\section{Previous studies assessing overall $\mathrm{HbA}_{1 \mathrm{c}}$ change with CSII therapy}

Overall improvements in $\mathrm{HbA}_{1 \mathrm{c}}$ in this study are broadly in keeping with the published literature. Taken as a whole, we found an adjusted mean $(95 \% \mathrm{CI}) \mathrm{HbA}_{1 \mathrm{c}}$ change of -4.3 (5.8 to -2.8$) \mathrm{mmol} / \mathrm{mol}(-0.3 \%)$. A Cochrane Collaboration systematic review published in 2010 including data from 23 randomized studies and 976 people with Type 1 diabetes found that CSII therapy was associated with an $\mathrm{HbA}_{1 \mathrm{c}}$ lowering of 0.3 (95\% CI: -0.1 to -0.4$) \%$ [21].

In recently published data from another large UK centre (King's College Hospital, London; 327 individuals; $71 \%$ female; pre-CSII $\mathrm{HbA}_{1 \mathrm{c}}=70 \mathrm{mmol} / \mathrm{mol}$ ), mean $\mathrm{HbA}_{1 \mathrm{c}}$ fell by $8 \mathrm{mmol} / \mathrm{mol}(0.7 \%)$ at year 1 and was maintained to year 5 [7]. The overall unadjusted mean change in our cohort was $7 \mathrm{mmol} / \mathrm{mol}(0.6 \%)$. In keeping with our data on the relationship between pre-CSII $\mathrm{HbA}_{1 \mathrm{c}}$ and $\mathrm{HbA}_{1 \mathrm{c}}$ change, those individuals with poor control (mean pre- 
CSII HbA $1 \mathrm{c}: 79 \mathrm{mmol} / \mathrm{mol} ; 9.4 \%)$, experienced a $12 \mathrm{mmol} / \mathrm{mol}(1.1 \%)$ reduction in $\mathrm{HbA}_{1 \mathrm{c}}$ at year 1 that extended to year 6. In comparison, we found a mean change in $\mathrm{HbA}_{1 \mathrm{c}}$ at 1 year of $10 \mathrm{mmol} / \mathrm{mol}(0.9 \%)$ in individuals with a pre-CSII $\mathrm{HbA}_{1 \mathrm{c}} \geq 64 \mathrm{mmol} / \mathrm{mol}(\geq 8.0 \%)$ and a mean change of $12 \mathrm{mmol} / \mathrm{mol}(1.1 \%)$ in those with a pre-CSII $\geq 69 \mathrm{mmol} / \mathrm{mol}(\geq 8.5 \%)$. In contrast to King's College Hospital, where the majority of individuals received structured education, only a small proportion of individuals in our study received formal structured education prior to pump therapy. It is interesting that despite this difference, broadly similar outcomes were obtained with CSII therapy.

\section{Individual patient responses}

Our data highlight significant between-patient variation in $\mathrm{HbA}_{1 \mathrm{c}}$ responses, even after adjustment for baseline factors. Although difficult to compare directly, individual variability appears to be much higher in our data compared with that from King's College Hospital. Previous studies have found that other factors including socio-economic status, depression, anxiety and fear of hypoglycaemia might affect glycaemic outcomes [22]. Further studies are required to understand the full impact of individual variation in response to CSII within the UK context. In our study, users of the Roche pump seem to have switched to other pumps much more often. Our data cannot determine the reasons for these observations, but individual usability factors may have played a role.

\section{Strengths and limitations}

Our study has several important strengths. First, this is the first to compare long-term changes in $\mathrm{HbA}_{1 \mathrm{c}}$ associated with different pump makes under routine care conditions. Second, we used yearly averaged pre- and post-CSII $\mathrm{HbA}_{1 \mathrm{c}}$ levels to maximize precision in estimating the change in glycaemic control. Third, the study had a large sample size and long duration of 
follow-up. Fourth, the study provides data on a clinic cohort that is likely to be generalizable to many other clinics worldwide. Fifth, the study had adequate power to detect clinically meaningful between-pump differences in $\mathrm{HbA}_{1 \mathrm{c}}$ of around $3 \mathrm{mmol} / \mathrm{mol}$ or more (Table 2). Finally, appropriate statistical methods were used to assess associations of CSII models with time-varying $\mathrm{HbA}_{1 \mathrm{c}}$ changes while accounting for potential confounding variables including pre-CSII HbA1c.

We acknowledge some limitations. First, this was a single-centre study, observational in nature, and therefore caution is required in the interpretation of our findings, particularly with regard to causation and the generalizability of the results. We cannot separate the effects of education received after starting CSII from CSII use. So the benefits may be a mixed effect. A variable number of individuals used the different pumps, and there were differences in baseline clinical characteristics and the availability of some CSII models over time. Although we expect no systematic difference, our database did not record the contact time and number of clinic visits between different pump users or information about pregnancy. However, these limitations are integral to a retrospective observational study design, during routine care and the measurable differences were accounted for in the statistical analysis. Second, we had limited data on rates of hypoglycaemia. Third, we had limited information on psychosocial factors and the usability of pumps, which might have influenced patient choice of CSII and perhaps between-pump differences in $\mathrm{HbA}_{1 \mathrm{c}}$ lowering. Fourth, we do not have data on pump failure rate. Finally, we do not have information on the proportion of individuals that were using continuous glucose monitors, although this is likely to be $<5 \%$ of all individuals because sensors were not funded by UK NHS at the time. 


\section{Clinical and research implications}

We showed similar $\mathrm{HbA}_{1 \mathrm{c}}$ lowering using different CSII models. Therefore, the choice of CSII make should be made according to the individual patient's preference. In addition, new pumps like the Medtronic 640g, which has additional features such as predictive low glucose suspend, may be more suitable for individuals with problematic hypoglycaemia. There is a need for large prospective studies to understand the influence of human traits including psycho-socio-economic factors on CSII outcomes including incident hypoglycaemia.

\section{Conclusions}

Under routine care conditions, there were no differences in adjusted $\mathrm{HbA}_{1 \mathrm{c}}$ lowering when comparing different pump makes, including a comparison of patch pumps vs. traditional catheter pumps. Changes in $\mathrm{HbA}_{1 \mathrm{c}}$ were maintained long-term and were related to pre-CSII $\mathrm{HbA}_{1 \mathrm{c}}$ level, diabetes duration and years using CSII.

\section{Funding sources}

None.

\section{Competing interests}

LL reports having received speaker honoraria from Minimed Medtronic, Animas and Novo Nordisk, serving on advisory panel for Animas and Novo Nordisk

\section{Acknowledgements}

This article is protected by copyright. All rights reserved. 


\section{Author contributions}

LL had full access to all the data in the study and takes responsibility for the integrity of the data. LL and SAR take responsibility for the accuracy of the data analysis. LL and MKR codesigned the study. AH, KM, TA, AC, JM, AU and PJ collected data. SAR carried out the data and statistical analyses. LL, MKR, SAR, AH, KM, AC, JM, AU and PJ contributed to the interpretation of the results. LL, SAR and MKR wrote the manuscript. All authors critically reviewed the report. No writing assistance was provided. Dr Rob Davies, AC, JM, AU and PJ provided patient care.

\section{References}

1 Pickup JC. Insulin-pump therapy for type 1 diabetes mellitus. $N$ Engl J Med 2012; 366: $1616-1624$.

2 Pickup JC, Sutton AJ. Severe hypoglycaemia and glycaemic control in Type 1 diabetes: meta-analysis of multiple daily insulin injections compared with continuous subcutaneous insulin infusion. Diabet Med 2008; 25: 765-774.

3 Steineck I, Cederholm J, Eliasson B, Rawshani A, Eeg-Olofsson K, Svensson AM et al. Insulin pump therapy, multiple daily injections, and cardiovascular mortality in 18,168 people with type 1 diabetes: observational study. BMJ 2015; 350: h3234.

$4 \quad$ Renard E. Insulin pump use in Europe. Diabetes Technol Ther 2010; 12(Suppl 1): S29S32.

5 McKnight JA, Wild SH, Lamb MJ, Cooper MN, Jones TW, Davis EA et al. Glycaemic control of Type 1 diabetes in clinical practice early in the 21 st century: an international comparison. Diabet Med 2015; 32: 1036-1050.

This article is protected by copyright. All rights reserved. 
6 Miller KM, Foster NC, Beck RW, Bergenstal RM, DuBose SN, DiMeglio LA et al. Current state of type 1 diabetes treatment in the U.S.: updated data from the T1D Exchange clinic registry. Diabetes Care 2015; 38: 971-978.

7 Beato-Vibora P, Yeoh E, Rogers H, Hopkins D, Amiel SA, Choudhary P. Sustained benefit of continuous subcutaneous insulin infusion on glycaemic control and hypoglycaemia in adults with Type 1 diabetes. Diabet Med 2015; 32: 1453-1459.

8 Joubert M, Morera J, Vicente A, Rod A, Parienti JJ, Reznik Y. Cross-sectional survey and retrospective analysis of a large cohort of adults with type 1 diabetes with longterm continuous subcutaneous insulin infusion treatment. J Diabetes Sci Technol 2014; 8: $1005-1010$.

9 Orr CJ, Hopman W, Yen JL, Houlden RL. Long-term efficacy of insulin pump therapy on glycemic control in adults with type 1 diabetes mellitus. Diabetes Technol Ther 2015; 17: 49-54.

10 Jahn LG, Capurro JJ, Levy BL. Comparative dose accuracy of durable and patch insulin infusion pumps. J Diabetes Sci Technol 2013; 7: 1011-1020.

11 Borot S, Franc S, Cristante J, Penfornis A, Benhamou PY, Guerci B et al. Accuracy of a new patch pump based on a microelectromechanical system (MEMS) compared to other commercially available insulin pumps: results of the first in vitro and in vivo studies. J Diabetes Sci Technol 2014; 8: 1133-1141.

12 Zisser H, Bevier W, Dassau E, Jovanovic L. Siphon effects on continuous subcutaneous insulin infusion pump delivery performance. J Diabetes Sci Technol 2010; 4: 98-103.

This article is protected by copyright. All rights reserved. 
13 Zisser H, Robinson L, Bevier W, Dassau E, Ellingsen C, Doyle FJ et al. Bolus calculator: a review of four 'smart' insulin pumps. Diabetes Technol Ther 2008; 10: $441-444$.

14 Zisser H, Wagner R, Pleus S, Haug C, Jendrike N, Parkin C et al. Clinical performance of three bolus calculators in subjects with type 1 diabetes mellitus: a head-to-head-tohead comparison. Diabetes Technol Ther 2010; 12: 955-961.

15 Pickup JC, Hammond P. NICE guidance on continuous subcutaneous insulin infusion 2008: review of the technology appraisal guidance. Diabet Med 2009; 26: 1-4.

16 Zisser H. Insulin pump (dose-to-dose) accuracy: what does it mean and when is it important? J Diabetes Sci Technol 2014; 8: 1142-1144.

17 Luijf YM, Arnolds S, Avogaro A, Benesch C, Bruttomesso D, Farret A et al. Patch pump versus conventional pump: postprandial glycemic excursions and the influence of wear time. Diabetes Technol Ther 2013; 15: 575-579.

18 Cohen ND, Hong ES, Van Drie C, Balkau B, Shaw J. Long-term metabolic effects of continuous subcutaneous insulin infusion therapy in type 1 diabetes. Diabetes Technol Ther 2013; 15: 544-549.

19 Papargyri P, Ojeda Rodriguez S, Corrales Hernandez JJ, Mories Alvarez MT, Recio Cordova JM, Delgado Gomez M et al. An observational 7-year study of continuous subcutaneous insulin infusion for the treatment of type 1 diabetes mellitus. Endocrinol Nutr 2014; 61: 141-146.

This article is protected by copyright. All rights reserved. 
20 Carlsson BM, Attvall S, Clements M, Gumpeny SR, Pivodic A, Sternemalm L et al. Insulin pump-long-term effects on glycemic control: an observational study at 10 diabetes clinics in Sweden. Diabetes Technol Ther 2013; 15: 302-307.

21 Misso ML, Egberts KJ, Page M, O'Connor D, Shaw J. Continuous subcutaneous insulin infusion (CSII) versus multiple insulin injections for type 1 diabetes mellitus. Cochrane Database of Systematic Reviews 2010: CD005103.

\section{Simmons JH, Chen V, Miller KM, McGill JB, Bergenstal RM, Goland RS et al. Differences in the management of type 1 diabetes among adults under excellent control compared with those under poor control in the T1D Exchange Clinic Registry. Diabetes} Care 2013; 36: 3573-3577.

FIGURE 1 Trends in $\mathrm{HBA}_{1 \mathrm{c}}$ by duration of continuous subcutaneous insulin infusion (CSII) therapy (a) and change in $\mathrm{HbA}_{1 \mathrm{c}}$ according to pre-CSII $\mathrm{HBA}_{1 \mathrm{c}}$ (b). Grey boxplots/points show the raw data for each individual:

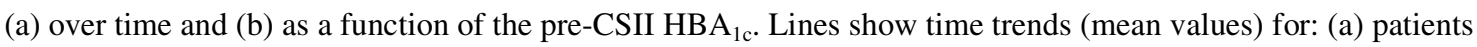
with pre-CSII $\mathrm{HBA}_{1 \mathrm{c}}$ at the three selected values, and (b) individuals with 1 and 5 years using pump therapy. Lines represent a simple smoothing of the data to aid visualization and represent smoothed mean values at the times/baseline values indicated. The lines are derived from a longitudinal regression model over time and $\mathrm{HBA}_{1 \mathrm{c}}$ using a quadratic smoothing function. DCCT, Diabetes Control and Complications Trial.

FIGURE 2 Unadjusted and covariate-adjusted mean (95\% CI) $\mathrm{HbA}_{1 \mathrm{c}}$ changes from baseline by pump make: $(\mathrm{a}, \mathrm{b})$ overall and $(\mathrm{c}, \mathrm{d})$ stratified by pre-pump $\mathrm{HBA}_{1 \mathrm{c}}$. Adjusted plots show data in each subgroup adjusted for all covariates (calendar year of pump commencement, sex, age started pump, duration of diabetes and baseline $\mathrm{HBA}_{1 \mathrm{c}}$ ) except the one defining the subgroup. DCCT, Diabetes Control and Complications Trial. 


\section{Supporting Information}

Additional Supporting Information may be found in the online version of this article.

Table $\mathbf{S 1 ~} \mathrm{HbA}_{1 \mathrm{c}}$ by year for the whole cohort.

Table $\mathbf{S 2} \mathrm{HbA}_{1 \mathrm{c}}$ by year for patients with poor control at baseline.

Table S3 Numbers, age, gender and $\mathrm{HbA}_{1 \mathrm{c}}$ from each of the four different pumps from pre-commencement to 5 years.

Figure S1 Unadjusted mean $\mathrm{HBA}_{1 \mathrm{c}}$ levels and change from baseline by pump and duration of pump use.

Figure S2 Unadjusted and covariate-adjusted mean $\mathrm{HbA}_{1 \mathrm{c}}$ changes from baseline by pump make.

Figure S3 Kaplan-Meier curves for the time to switching for each pump type. 
Table 1 Baseline characteristics of the study population

\begin{tabular}{|c|c|c|c|c|c|c|}
\hline & Whole cohort & Medtronic & Omnipod & Roche & Animas & $P$ \\
\hline$n$ & 508 & 254 & 120 & 71 & 63 & \\
\hline Women & $282(55)$ & $150(59)$ & $54(45)$ & $38(54)$ & $40(64)$ & 0.039 \\
\hline Type 1 diabetes & $478(94)$ & $240(95)$ & $115(96)$ & $66(93)$ & $57(91)$ & 0.18 \\
\hline Duration of diabetes, & $19.7(11.5-$ & $21.1(12.9-$ & $19.1(8.5-$ & $18.1(8.2-$ & $17.1(10.7-$ & 0.024 \\
\hline years & 28.9) & $30.9)^{*}$ & $28.2) \dagger$ & $23.5) \ddagger$ & $33.1)$ & \\
\hline \multirow[t]{2}{*}{ Age at start of CSII, years } & $39.9(29.6-$ & $41.3(32.2-$ & $36.3(27.4-$ & $38.4(29.6-$ & $43.4(28.8-$ & 0.007 \\
\hline & 49.1) & $51.3)$ & 47.8) & 43.7) & 48.8) & \\
\hline \multicolumn{7}{|l|}{ Year of starting CSII } \\
\hline $2000-2005$ & $14(2.8)$ & $14(6)$ & $0(0)$ & $0(0)$ & $0(0)$ & $<0.001$ \\
\hline 2006-2010 & $208(40.9)$ & $158(62)$ & $0(0)$ & $25(35)$ & $25(40)$ & \\
\hline 2011-2014 & $286(56.3)$ & $82(32)$ & $120(100)$ & $46(65)$ & $38(60)$ & \\
\hline Pre-CSII HBA1c, & $71(61.5-$ & $71(61.5-82.4)$ & $68.2(59.9-$ & $74.3(63.5-$ & $71.1(62-$ & 0.22 \\
\hline $\mathrm{mmol} / \mathrm{mol}$ & $82.7)$ & & 80.9) & $87.3)$ & $86.4)$ & \\
\hline $\mathrm{HBA}_{1 \mathrm{c}} \geq 64 \mathrm{mmol} / \mathrm{mol}$ & 345 (67.9) & $172(67.7)$ & $78(65)$ & $53(74.6)$ & $42(66.7)$ & 0.57 \\
\hline \multicolumn{7}{|l|}{ Insulin type } \\
\hline Novorapid & $351(69.5)$ & $175(69)^{1}$ & $94(79)^{1}$ & $43(61)^{1}$ & $39(62)$ & 0.12 \\
\hline Humalog & $117(23.2)$ & $56(22)$ & $19(16)$ & $21(30)$ & $21(33)$ & \\
\hline Other & $37(7.3)$ & $22(9)$ & $6(5)$ & $6(9)$ & $3(5)$ & \\
\hline Duration of CSII, years & $3.7(2.5-5.1)$ & $4.6(3.7-6.7)$ & $2.1(1.6-2.7)$ & $3.5(2.5-4.5)$ & $3.7(2.8-4.7)$ & $<0.001$ \\
\hline
\end{tabular}

Data are median (IQR) or $n(\%) . P$-values from a Kruskal-Wallis or $\chi^{2}$ test between pump types.

Unknown for: *three individuals, †four individuals and $\ddagger$ one individual. 
Table 2 Potential factors that might be associated with improvements in $\mathrm{HbA}_{1 \mathrm{c}}$ based on 1786 observations from 480 individuals

\begin{tabular}{|c|c|c|c|c|}
\hline & Parameter & $\begin{array}{l}\text { Difference in } \mathrm{HbA}_{1 \mathrm{c}} \\
\text { improvement } \\
(\mathrm{mmol} / \mathrm{mol})\end{array}$ & $95 \% \mathrm{CI}$ & $P$ \\
\hline \multirow[t]{4}{*}{ Pump type } & Medtronic & $-3.26^{*}$ & $(-5.26$ to -1.27$)$ & 0.44 \\
\hline & Animas & $-4.41 *$ & $(-7.19$ to -1.64$)$ & \\
\hline & Roche & $-5.52 *$ & $(-8.19$ to -2.85$)$ & \\
\hline & Omnipod & $-5.02 *$ & $(-7.43$ to -2.62$)$ & \\
\hline Sex & Female v Male & -0.78 & $(-2.58$ to 1.01$)$ & 0.393 \\
\hline Duration of diabetes & Years from median & -0.1 & $(-0.19$ to -0.02$)$ & 0.017 \\
\hline Age when pump use & Decades from median & -0.027 & $(-0.873$ to 0.82$)$ & 0.951 \\
\hline \multicolumn{5}{|l|}{ started } \\
\hline Start year & Year-2011 & 0.32 & $(-0.22$ to 0.86$)$ & 0.248 \\
\hline \multirow[t]{2}{*}{ Years on pump } & Linear term at year 1 & 0.11 & $(-0.4$ to 0.62$)$ & 0.024 \\
\hline & Quadratic term & -0.065 & $(-0.134$ to 0.004$)$ & \\
\hline \multirow[t]{2}{*}{ Pre-pump $\mathrm{HBA}_{1 \mathrm{c}}$} & Linear term at median & -0.36 & $(-0.41$ to -0.3$)$ & $<0.001$ \\
\hline & Quadratic term & -0.002 & $(-0.0034$ to -0.0005$)$ & \\
\hline
\end{tabular}

Effects are estimated using a multivariable longitudinal model including all the parameters listed in the table.

Two variables are represented by a quadratic function and therefore have two parameters representing the linear and quadratic components; these are centred at year 1 (for years on pump) and the median initial $\mathrm{HbA}_{1 \mathrm{c}} ; P$ values are given for the combined time and baseline effects. $P$-values for pump type, years on pump and prepump $\mathrm{HBA}_{1 \mathrm{c}}$ are presented for the overall effects, not the individual terms in the model.

*Mean values for each pump type at the reference level for the other variables. 
Figure 1: panel (a)

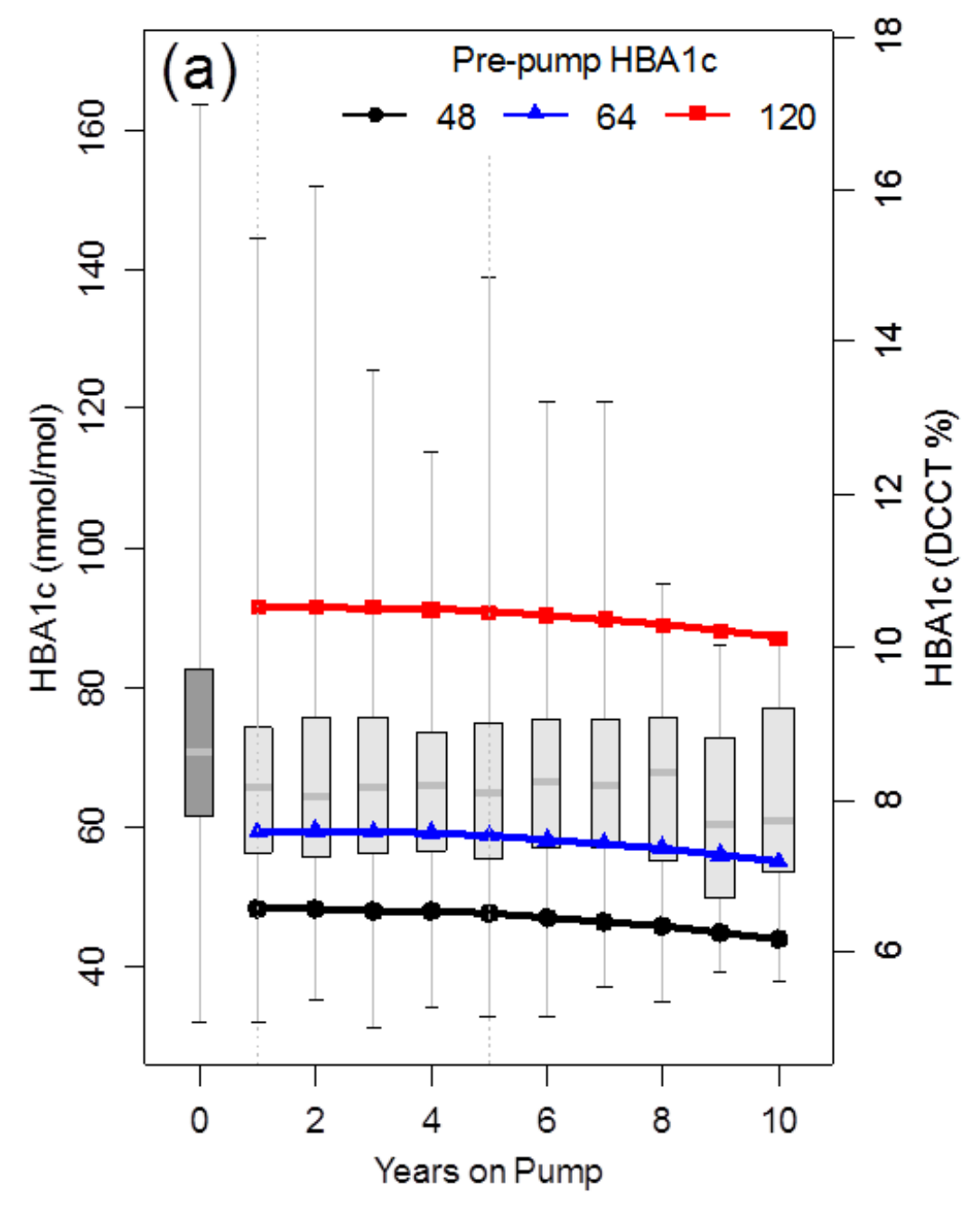


Figure 1: panel (b)

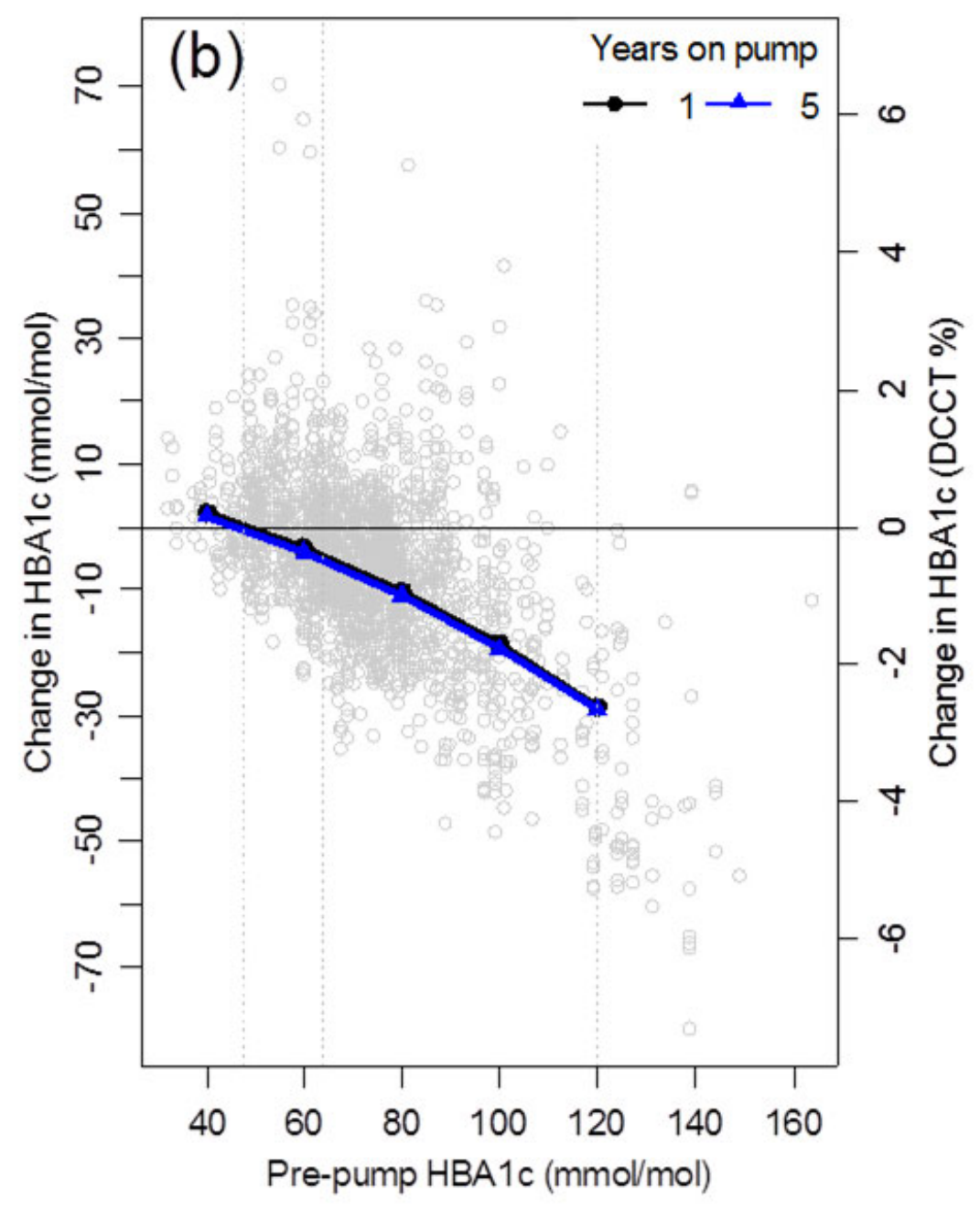


Fig 2 -Panel (a)

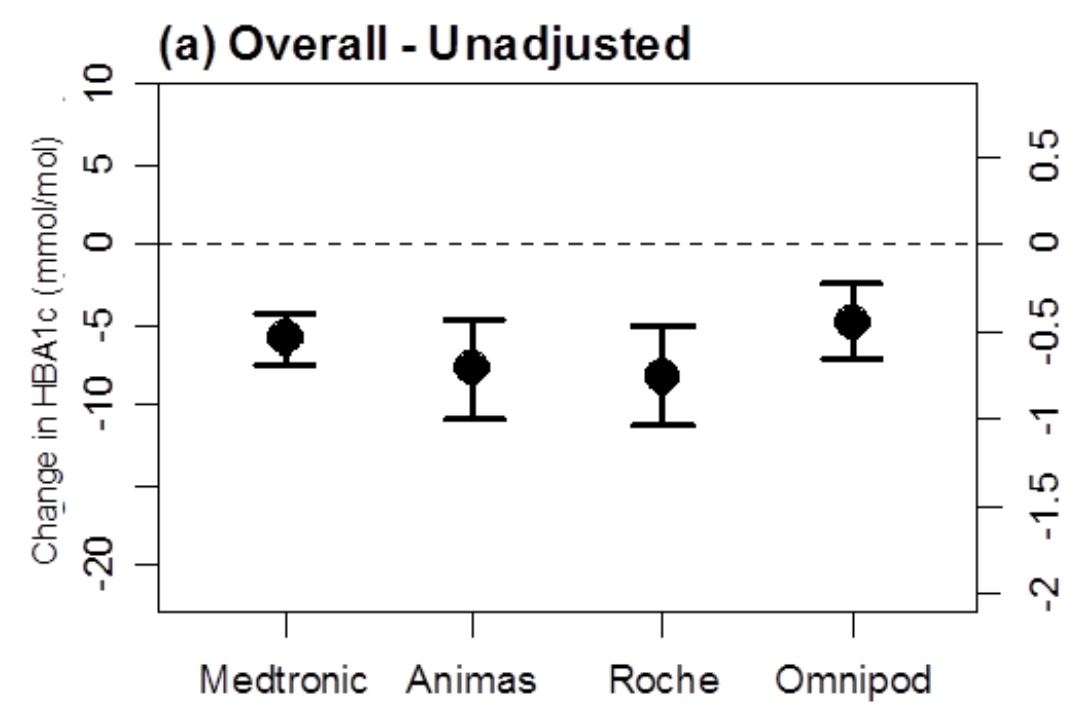


Fig 2 -panel (b)

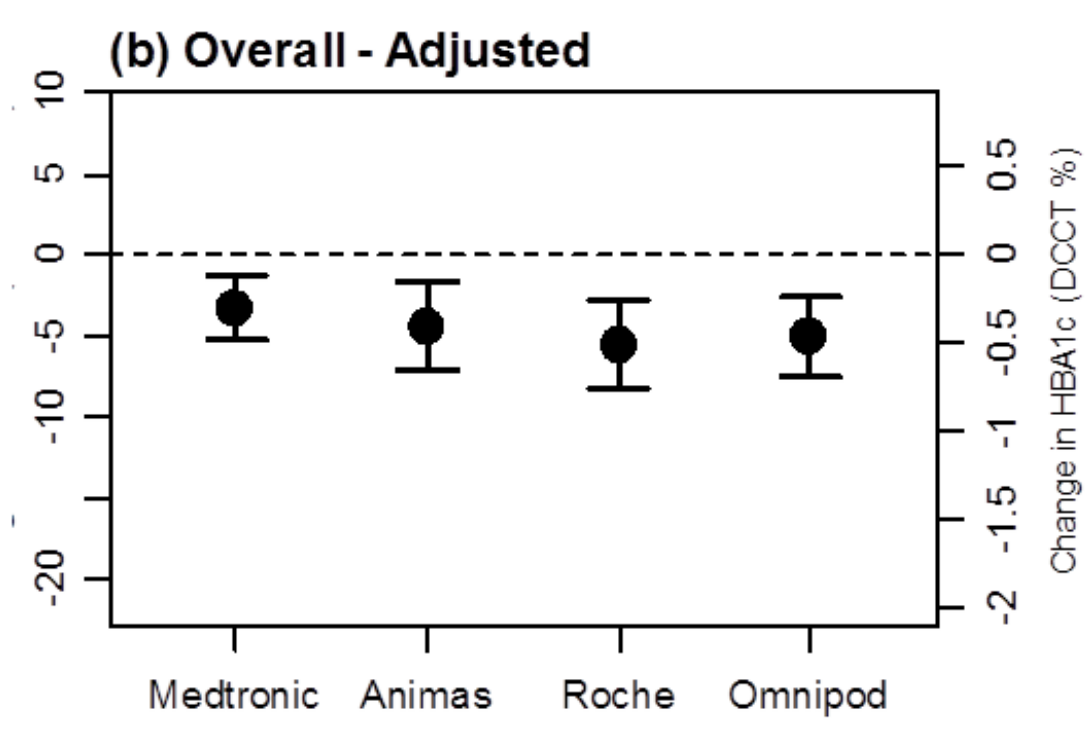


Fig 2 - panel (c)

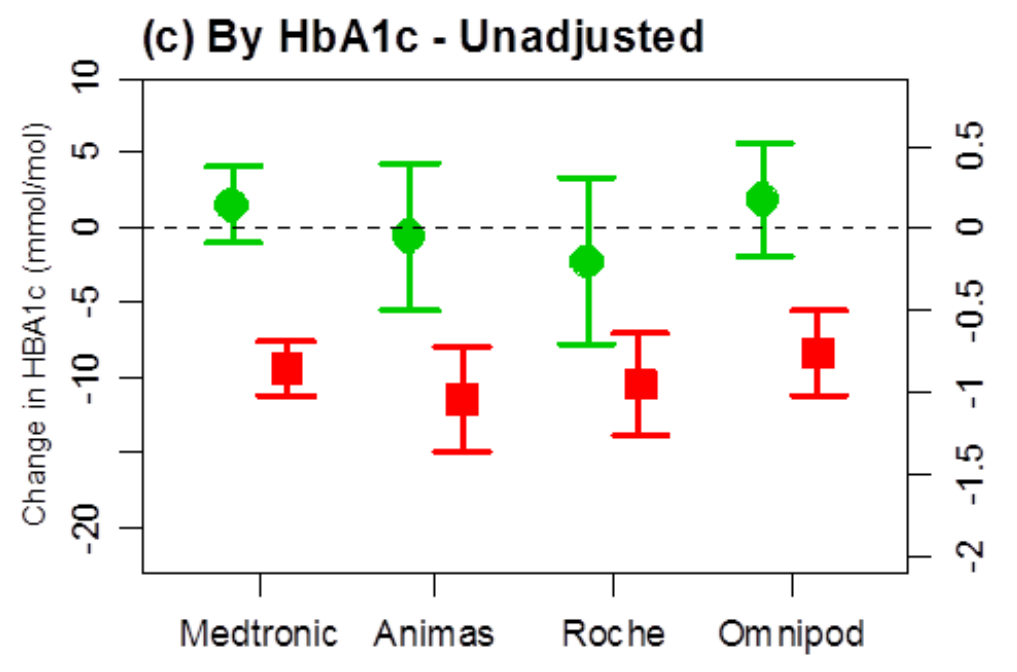


Fig 2 -panel (d)

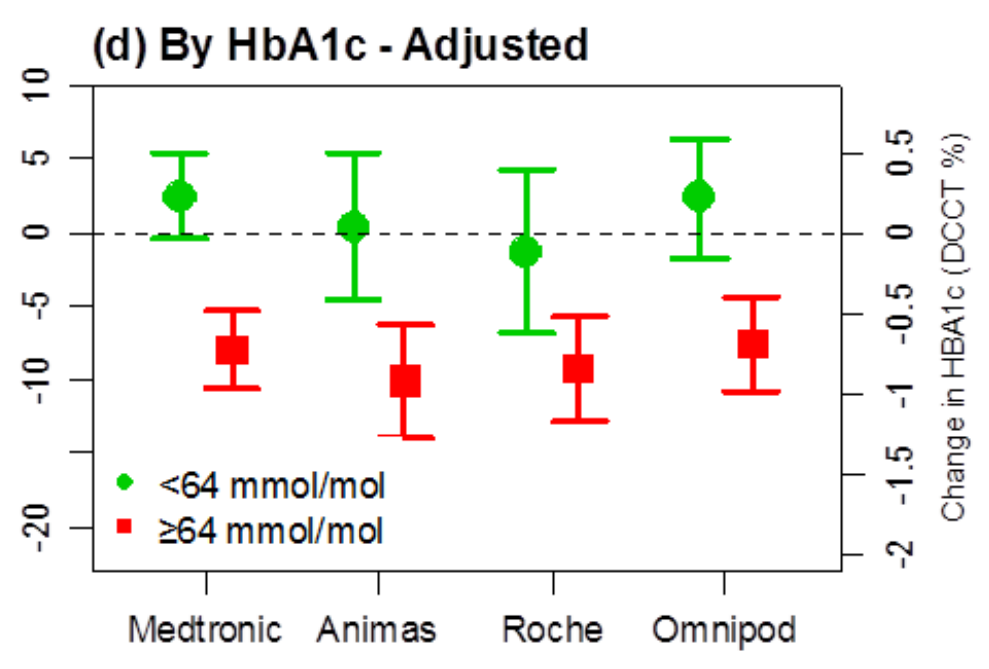

